\title{
Glioma stem cells invasive phenotype at optimal stiffness is driven by MGAT5 dependent mechanosensing
}

Emilie Marhuenda ${ }^{1,2,3^{*}}$ (D) Christine Fabre ${ }^{1,4}$, Cunjie Zhang ${ }^{5,6}$, Martà Martin-Fernandez ${ }^{7}$, Thomas Iskratsch², Ali Saleh", Luc Bauchet ${ }^{1}$, Julien Cambedouzou ${ }^{3,4}$, Jean-Philippe Hugnot ${ }^{1}$, Hugues Duffau', James W. Dennis ${ }^{5,6}$, David Cornu ${ }^{3,4^{*}+}$ and Norbert Bakalara ${ }^{1,4^{*}+}$

\begin{abstract}
Background: Glioblastomas stem-like cells (GSCs) by invading the brain parenchyma, remains after resection and radiotherapy and the tumoral microenvironment become stiffer. GSC invasion is reported as stiffness sensitive and associated with altered N-glycosylation pattern. Glycocalyx thickness modulates integrins mechanosensing, but details remain elusive and glycosylation enzymes involved are unknown. Here, we studied the association between matrix stiffness modulation, GSC migration and MGAT5 induced N-glycosylation in fibrillar 3D context.

Method: To mimic the extracellular matrix fibrillar microenvironments, we designed 3D-ex-polyacrylonitrile nanofibers scaffolds (NFS) with adjustable stiffnesses by loading multiwall carbon nanotubes (MWCNT). GSCs neurosphere were plated on NFSs, allowing GSCs migration and MGAT5 was deleted using CRISPR-Cas9.

Results: We found that migration of GSCs was maximum at $166 \mathrm{kPa}$. Migration rate was correlated with cell shape, expression and maturation of focal adhesion (FA), Epithelial to Mesenchymal Transition (EMT) proteins and $(\beta 1,6)$ branched N-glycan binding, galectin-3. Mutation of MGAT5 in GSC inhibited N-glycans ( $\beta 1-6)$ branching, suppressed the stiffness dependence of migration on $166 \mathrm{kPa}$ NFS as well as the associated FA and EMT protein expression.
\end{abstract}

Conclusion: MGAT5 catalysing multibranched N-glycans is a critical regulators of stiffness induced invasion and GSCs mechanotransduction, underpinning MGAT5 as a serious target to treat cancer.

Keywords: Mechanotransduction, 3D-nanofibre scaffold, Biomaterial, Stiffness, Glycosylation, Mgat5, Galectin, Focal adhesion, EMT, Migration, Glioblastoma

\footnotetext{
*Correspondence: e.marhuenda@qmul.ac.uk; david.cornu@enscm.fr; norbert.bakalara@enstbb.fr

${ }^{\dagger}$ David Cornu and Norbert Bakalara are co-last author.

${ }^{1}$ Institut des Neurosciences de Montpellier (INM) U-1051, University of

Montpellier, 80 rue Augustin Fliche, Hôpital Saint-Eloi, 34091 Montpellier,

Cedex 5, France

${ }^{3}$ Institut Européen des Membranes, IEM, UMR 5635, University of Montpellier, ENSCM, CNRS, Montpellier, France

Full list of author information is available at the end of the article
}

(c) The Author(s). 2021 Open Access This article is licensed under a Creative Commons Attribution 4.0 International License, which permits use, sharing, adaptation, distribution and reproduction in any medium or format, as long as you give appropriate credit to the original author(s) and the source, provide a link to the Creative Commons licence, and indicate if changes were made. The images or other third party material in this article are included in the article's Creative Commons licence, unless indicated otherwise in a credit line to the material. If material is not included in the article's Creative Commons licence and your intended use is not permitted by statutory regulation or exceeds the permitted use, you will need to obtain permission directly from the copyright holder. To view a copy of this licence, visit http://creativecommons.org/licenses/by/4.0/ The Creative Commons Public Domain Dedication waiver (http://creativecommons.org/publicdomain/zero/1.0/) applies to the data made available in this article, unless otherwise stated in a credit line to the data. 


\section{Background}

Glioblastoma multiforme (GBM) is the most aggressive form of brain cancer with a highly invasive nature that impedes complete surgical removal, making relapse inevitable. However, the molecular mechanisms of Glioma stem cells (GSC) invasion into the surrounding tissue are still unclear. Clinical observations by Scherer (1938) [1], demonstrated that glioma cells preferentially migrate in fibrous areas [2]. Extra Cellular Matrix (ECM) stiffness is reported to increase during tumor growth and from low grade glioma to GBM [3], whereby tissue stiffness has been suggested to modulate GSCs migration capacity [2] and tumour progression. These gliomainduced changes in ECM stiffness are accompanied by changes of the glioma cell morphology and nuclear volume [4] and promote epithelial to mesenchymal transition (EMT) [2]. The natural ECM fibrillar architecture is critical for 3D mechanosignalling events such as focal adhesions (FA) formation [5] and fibre alignment has therefore been reported to greatly influence migration. However, little is known about stiffness impact of fibrillar 3D environment on migration.

Primary glioblastoma tumours and their derived tumour cell lines display cellular and molecular characteristics of mesenchymal stem cells, driving to an increase of migratory abilities, resistance to apoptosis, radio-resistance and production of ECM components [6, 7]. Mesenchymal-phenotype in GBM is mediated by the activation of transcription factors including SRY-related box 2 (SOX2) and Zinc finger E-box binding homeobox 1 (ZEB1) [8]. SOX2 overexpression is also associated with a bulky glycocalyx which potentiates integrin mechanosignalling in glioma [9].

Coordination between FA dynamics and actin cytoskeleton is essential for cell migration [10]. FAs are the adhesion nexus between cells and the ECM [11], which consists of a series of dynamic protein complexes interactions [12] highly modulated by stiffness and mediate mechanosensing. The molecular pathways for force transmission through the FA depend on direct interactions between the ECM and integrins [13] as well as adaptor proteins that directly connect integrins to the actin cytoskeleton, such as talin [14], indirect interactions between integrins and actin mediated by vinculin [15] and signalling pathways such as the Focal Adhesion Kinase (FAK) [16]. Calpain2, an intracellular calcium-dependent cysteine protease, is involved in FA dynamics through modulation of talin and FAK structure and function [17] when bound to integrins [18].

Integrins have multiple site of $\mathrm{N}$-glycosylation that are remodelled in the Golgi, modulating their affinity for galectins. The galectins bind to the Nacetyllactosamine (LacNAc) epitopes, with affinities that increase with $\mathrm{N}$-glycan branching, catalysed by the Golgi N-acetylglucosaminyltransferase (MGAT) pathway comprising MGAT1, MGAT2, MGAT4a,b and MGAT5. The highly branched N-glycans catalysed by MGAT5 harbour the higher affinities for galectins $[19,20]$. The resulting galectin lattice displays rapid exchange of binding partners, thereby acting as an intermediary between free diffusion of glycoproteins, and more stable complexes notably the integrin-ECM focal adhesions [18, 21].

New concepts are emerging taking into account the role of glycocalyx and $\mathrm{N}$-glycosylation in mechanosensing process due to cell-ECM interactions, but there is no report demonstrating the direct role of a specific glycosylation enzyme regulating mechanotransduction and optimal directed migration.

We initially developed a NFS made of 3D electrospun ex-polyacrylonitrile which supported GSC migration in vitro reflecting the behaviour of glioblastomas in vivo [7]. Beyond specifically mimicking fibrous structures the NFS includes a 3D topology around the cells that reproduce heterogeneity, directionality, surface chemistries relevant to understand the behaviour of GSCs. Also, while migrating into the fibres matrix, GSCs exhibit mesenchymal and pre-metastatic stem cell markers such as ATXN1, ALCAM, CD9, ITGA7, CD44 and CHI3L1 according to transcriptomic profile [7]. Substratum fibril composition and MGAT5 expression individually have been shown to influence cell adhesion and migration with nonmonotonic dynamics $[18,21]$. In this paper we report the mechanosensing interaction existing between substratum stiffness and MGAT5 activity by profiling wild-type GSCs (WT GSC) and MGAT5 knock-out GSCs (MGAT5 KO GSC) seeded onto NFSs made with stiffnesses from 3 to $1260 \mathrm{kPa}$. Those stiffness values are in the range reported for human healthy tissues and gliomas [22], described as increasing U251 migration [23] and beyond in order to evaluate the potential linear relationship between stiffness and GSC invasiveness including brain stiffnesses nonreported in physiological or pathological context. The results reveal a requirement for both MGAT5 branched Nglycans and an optimum substratum stiffness for mechanotransduction of signalling and GSC invasiveness.

\section{Results}

NFSs of different stiffness are generated with the addition of different amount of MWCNTs

Four grades of NFSs were prepared by incorporating different amounts of MWCNTs. These nanotubes present a very high intrinsic Young's modulus and are consequently used to increase the Young's modulus of composite fibres [24]. The different NFSs respectively featured $0,0.0015$, 0.00635 and $0.05 \% \mathrm{w} / \mathrm{w}$ of MWCNTs in order to recapitulate a comparable cellular environment. To confirm the 
stiffness, atomic force microscope measurements were done in a liquid medium checking that the contact point was well applied on the surface of the fibre. For each grade, at least 5 areas were analysed (Figure S1). These results yield average Young's moduli of $3 \pm 2 \mathrm{kPa}, 166 \pm 29$ $\mathrm{kPa}, 542 \pm 90 \mathrm{kPa}$ and $1260 \pm 430 \mathrm{kPa}$, respectively, indicating an increase in stiffness as a function of MWCNT content (Fig. 1a).

The electrospinning technic allowed us to produce a NFS creating a biomimicking, confined environment for embedded cells as previously described (18). Its pore area distribution ranges between $0.5 \mu \mathrm{m}^{2}$ and $7 \mu \mathrm{m}^{2}$, with constant fibre morphology and diameter, independent of MWCNT content (Fig. 1b, c and d).

\section{$166 \mathrm{kPa}$ NFSs trigger optimal GSC motility}

NS of identical sizes were plated on NFSs of different stiffnesses and were allowed to migrate in differentiation medium for 5 days (Fig. 2a and b). GSCs grow at the same rate on NFS of different stiffnesses (Fig. 2c). GSCs migrate on NFS in a collective mode, irrespective of the stiffness of the fibres (Fig. $2 \mathrm{~b}$ and $\mathrm{d}$ ). However, on the $166 \mathrm{kPa}$ nanofibers a large number of GSCs migrated out of the NS, while migration was minimal on other nanofibers stiffnesses, and the migration area on $166 \mathrm{kPa}$ NFS was $\sim 4$ times larger than on NFSs of other stiffnesses (Fig. 2a, and e). We found similar results both in proliferation medium and differentiation medium. Proliferation medium is serum-free and supplemented with $\beta$-FGF and EGF which allows propagation of multipotent, self-renewing tumour-spheres (NS) [25]. On tissue culture, the cells remain largely stationary as NS in this medium, but on $166 \mathrm{kPa}$ nanofibers the glioma cells migrated (Fig. 2a and f). In our context, the optimal stiffness of $166 \mathrm{kPa}$ is sufficient to trigger

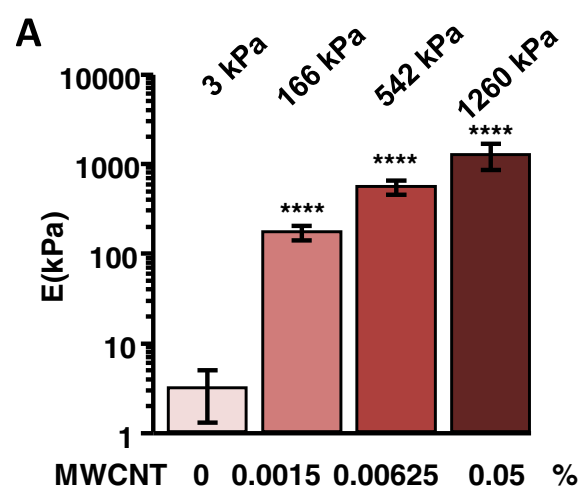

B
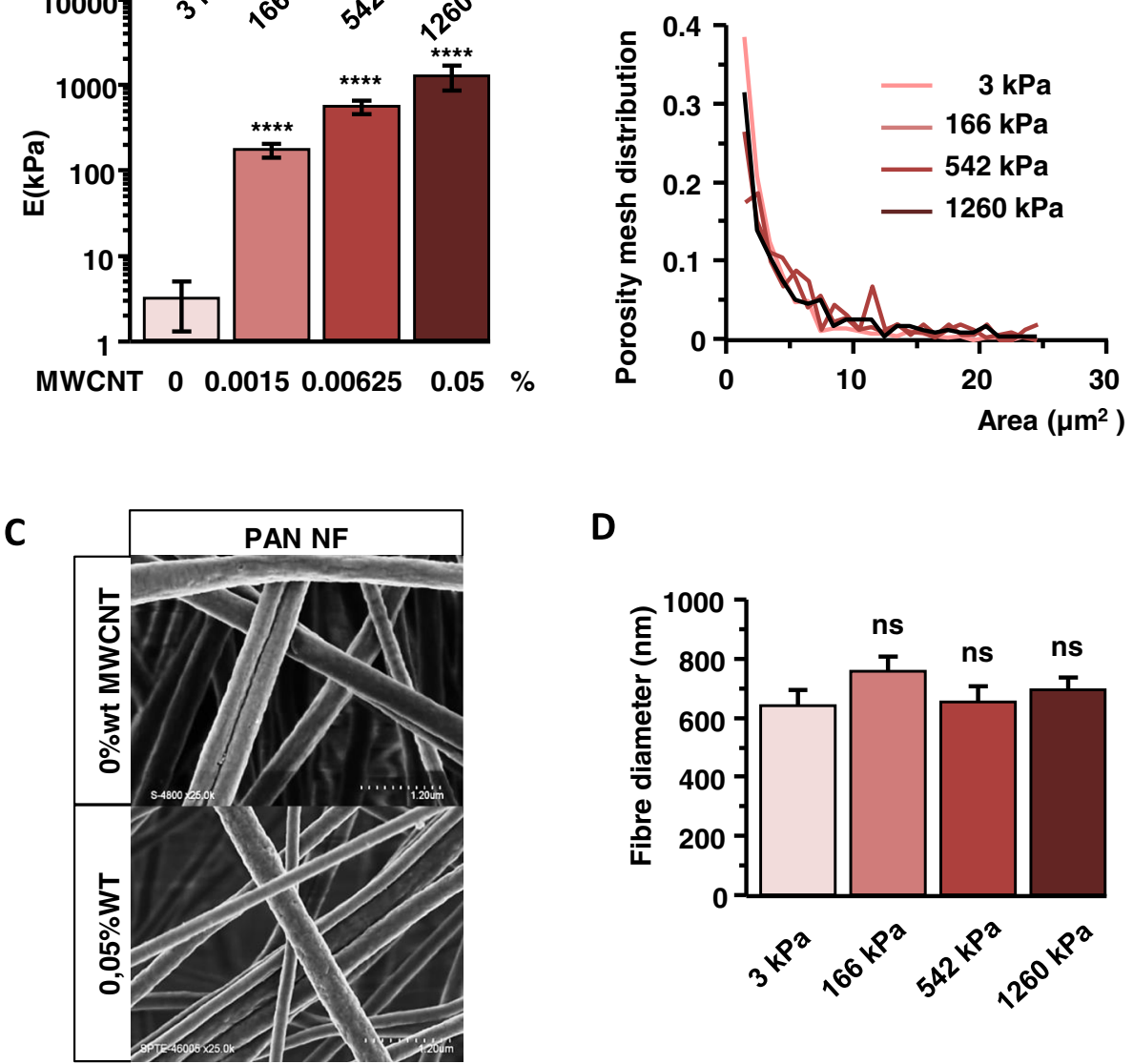

D

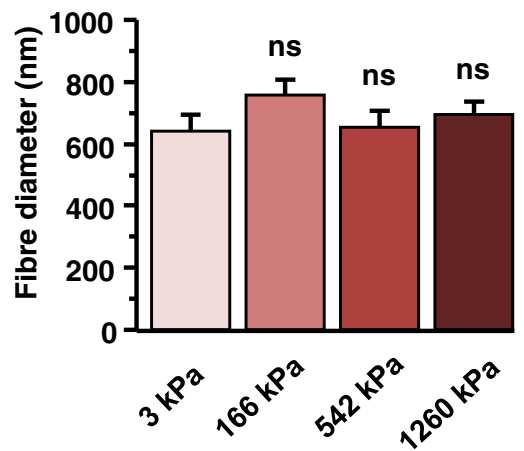

Fig. 1 Characterization of the NFS with MWCNTs. a Young's modulus increases as a function of MWCNT content. Bars represent the average of the Gaussian peaks fitted to the Young's modulus value distributions of individual force maps ( \pm SD). The number of analysed force maps is at least 5. The stiffness of the four samples are significantly different from one another ( $p<0.01$, one-way ANOVA). b Porosity distribution measured by confocal microscopy and 3D reconstitution. c Scanning electron microscopy images of fibres surface (Scale $1.20 \mu$ m). d Fibre diameter distribution ( \pm SEM). ( $^{*} p<0,05$; $\left.{ }^{* *} p<0,01 ; *^{* *} p<0,005 ; *^{* * *} p<0,001\right)$ Statistical significance was determined using one-way ANOVA with post hoc Tukey's Honest Significant Difference test for multiple comparisons 
A
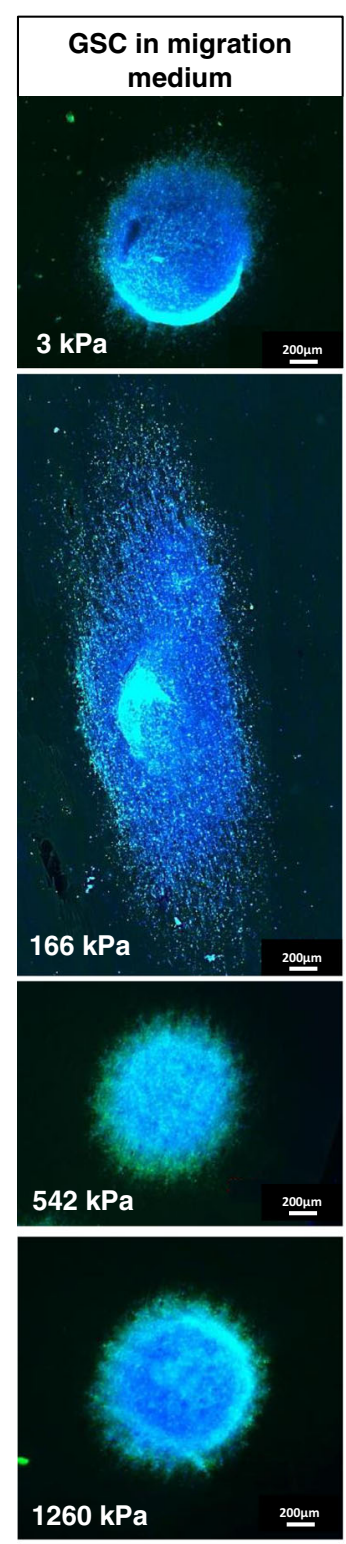
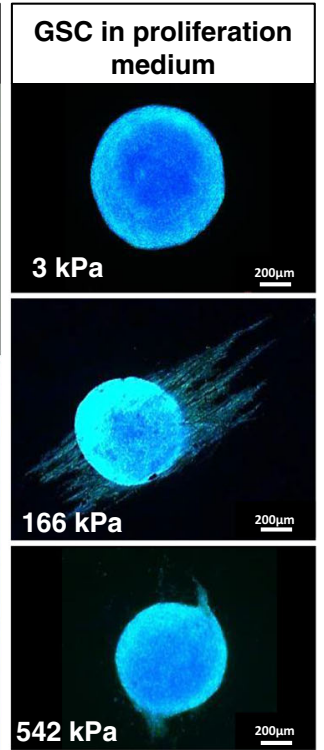

\section{$542 \mathrm{kPa}$}

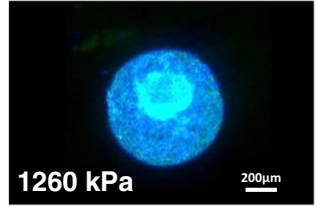

Hoechst

Phalloidin

B

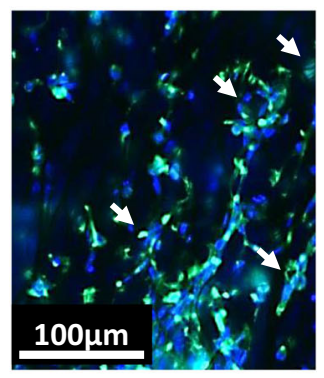

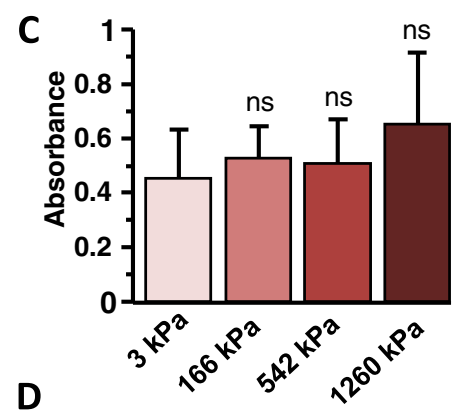

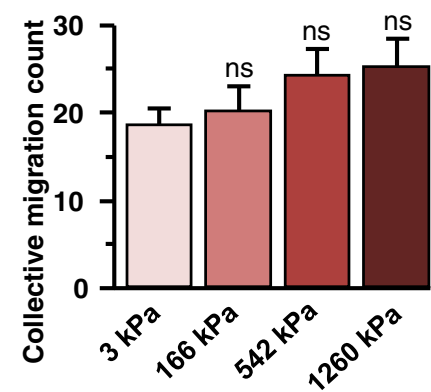

E

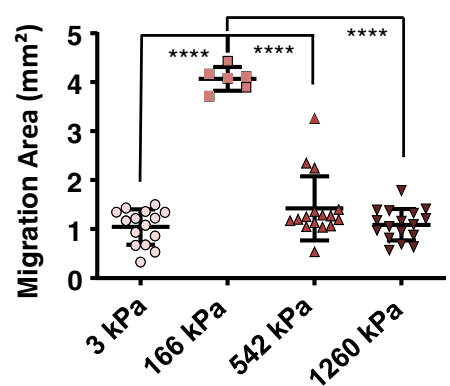

F

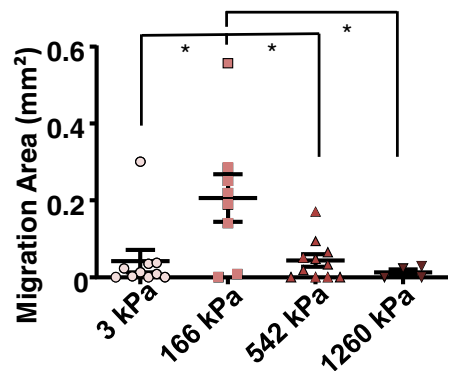

Fig. 2 Optimal migration of GSCS on $166 \mathrm{kPa}$ NFS. Migration was estimated by subtracting the area of the initial NS to the total area occupied by the NS and cells having migrated away from it within 5 days. a, b F-Actin was stained with the Phalloïdin (Green) and the nucleus stained with the Hoechst 33342 (Blue). a Left panel: in migration medium (Scale bar: $200 \mu \mathrm{m}$ ). Right panel: in proliferation medium (Scale bar: $200 \mu \mathrm{m})$. b A view of cells migrating on the $166 \mathrm{kPa}$ NFS at higher magnification. Collective migration were considerate for each aggregates composed at least by tens cells tightly associated (18). Arrows point at a few examples of collective migration (Scale bar: $100 \mu \mathrm{m}$ ). c 3000 dissociated GSCs were seeded on NFSs of different stiffnesses and proliferation was estimated with the MTT assay after 5 days of culture. No significant differences between conditions could be discerned $(n=3)$. $\mathbf{d}$ Collective migration quantification. e Migration areas in migration medium as a function of NFS stiffness showing appreciable migration only at $166 \mathrm{kPa}$ ( $n=3$ with at least 6 GSCs NS per condition). $\mathbf{f}$ Migration areas in proliferation medium as a function of NF stiffness showing appreciable migration only at $166 \mathrm{kPa}$ ( $n=3$ with at least 4 GSCs NS per condition). Values of the figure correspond to the mean \pm SEM and statistical significance was determined using one-way ANOVA, $\left({ }^{*} p<0,05 ;{ }^{* *} p<0,01 ;{ }^{* *} p<0,005\right.$; **** $p<0,001$ )

migration, something which is usually promoted in vitro in GSCs by the addition of serum to the medium. Cytotoxicity or changes in proliferation were not observed on NFSs of different stiffnesses.

\section{WT GSC morphology depends on NFS stiffness}

Directionality of migration is reflected a bipolar spindleshaped cell morphology driven by cytoskeleton rearrangement $[4,26,27]$. Cell morphology was examined 
by plating dissociated GSCs on in 2D NFSs (Fig. 3a), and after 5 days, we measured the cell length (Fig. 3b), width (Fig. 3c) and calculated width/length ratios (Fig. 3d). GSCs plated on NFSs were always thinner than GSC plated in 2D. The length of the GSCs cultivated on NFSs of 542 and $1260 \mathrm{kPa}$ were shorter than cells on NFSs of $3 \mathrm{kPa}$ and $166 \mathrm{kPa}$. The minimum width was observed for cells on NFS of $166 \mathrm{kPa}$ (Fig. 3a and c). The width/ length ratio indicates that the maximum morphological plasticity is reached for a stiffness of $166 \mathrm{kPa}$ (Fig. 3d). Cancer cell motility is associated with FA dynamics, and EMT phenotype $[2,28]$. We therefore investigated the expression of proteins implicated in EMT and/or cytoskeleton organisation next.

\section{A}
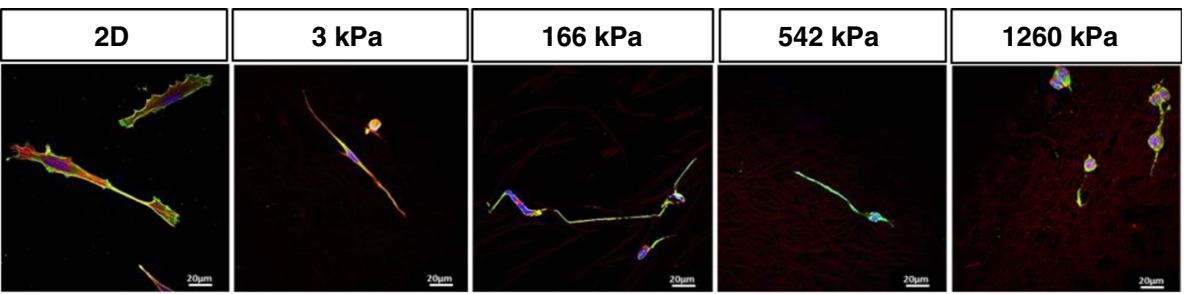

B

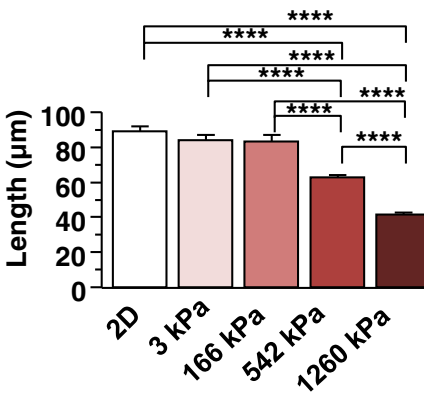

C

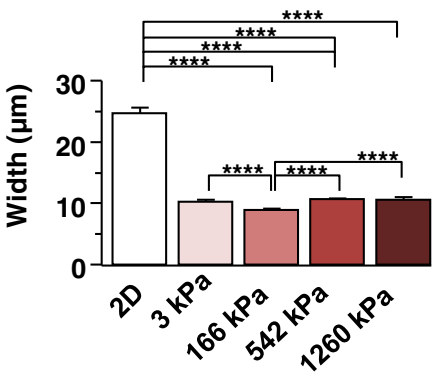

D
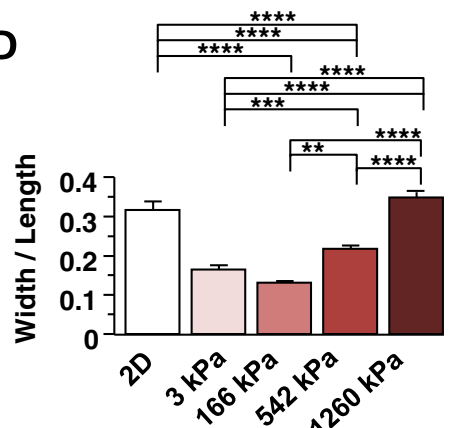

$\mathbf{E}$

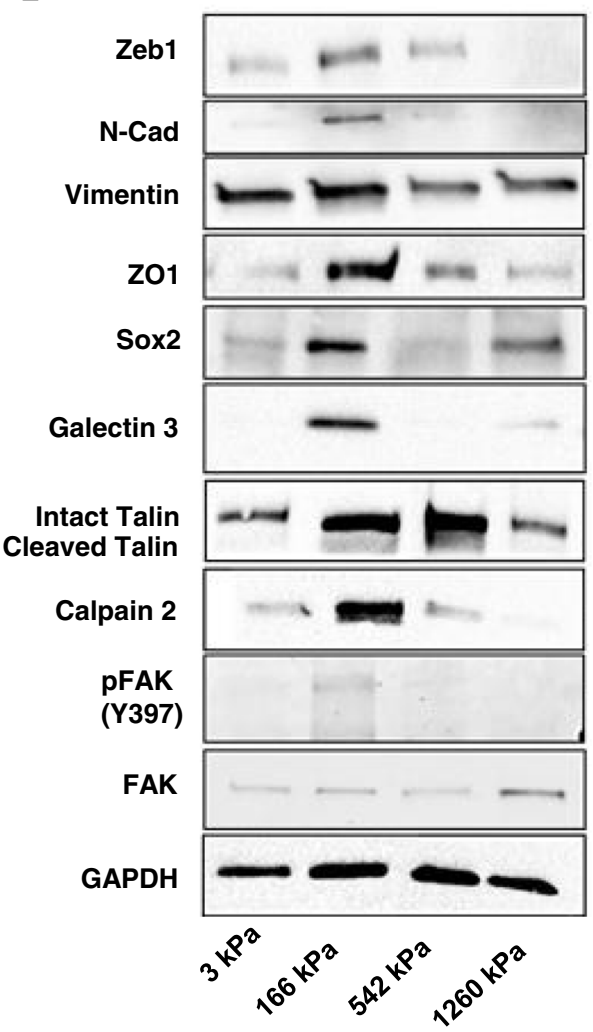

Fig. 3 Optimal stiffness increases EMT and FA maturation in GSCs. a GSCs were cultured on 2D and NFSs of different stiffnesses. Labelling: vinculin green, actin red (phalloidin) and DNA blue (Hoechst 33342). b Length, $\mathbf{c}$ Width and $\mathbf{d}$ aspect ratio of GSCs grown fibres of different stiffnesses were determined. Measurements were taken regarding to nucleus location. ( $n=3$ with at least 172 cells by condition) Values of the figure correspond to the mean \pm SEM and statistical significance was determined using one-way ANOVA $\left({ }^{*} p<0,05 ; *^{* *} p<0,01 ;{ }^{* * *} p<0,005 ;{ }^{* * * *}\right.$ $p<0,001)$. e Western Blot membranes showing EMT and focal adhesion protein expression in GSCs grown on NFSs with different stiffnesses. $(n=$ 3 to $n=7$ for each protein tested) Associated quantifications in Supp. Figure 2 
Expression of EMT and focal adhesion proteins is maximal on the $166 \mathrm{kPa}$ NFS

The expression of N-CAD, ZEB1 and SOX2 was higher in cells grown on $166 \mathrm{kPa}$ NFS than in cells cultured on the other NFSs (Fig. 3e and Figure S2). This agrees well with the higher motility GSCs observed on $166 \mathrm{kPa}$ NFS. Although, vimentin expression does not vary significantly with fibre stiffness (Fig. 3e and Figure S2), the tight junction protein $\mathrm{ZO} 1$ was selectively expressed in cells grown on $166 \mathrm{kPa}$ NFS (Fig. 3e and Figure S2). These data suggest that cell-cell junctions and their turnover may play a role in efficient collective migration at the optimal stiffness of $166 \mathrm{kPa}$.

FA maturation and signalling through integrin-ECM interactions, as well as FAK signalling modulate cell migration [9, 21]. FAK phosphorylation on tyrosine 397 (Y397) is associated with integrin mechanosensing as well as with integrin-mediated focal adhesion maturation and turnover [29]. The pFAK/FAK ratio was elevated in cells grown on $166 \mathrm{kPa}$ NFS compared with the NFSs of different stiffness (Fig. 3e and Figure S2), consistent with the relative migration rates (Fig. 2). The levels of calpain 2 , talin and its cleaved form are also highest in cells cultured on $166 \mathrm{kPa}$ NFS. These proteins are recruited to FA where calpain 2 promotes the recycling of these structures and contribute to migration [17, 29]. Integrins are modified with $\beta 1,6 \mathrm{GlcNAc}$ branched tetra-antennary $\mathrm{N}$-glycans are bound by Galectin-3 in a transient interaction that promotes FA remodelling depending also on stiffness of the ECM $[18,21,30]$. Galectin 3 levels are increased in cells grown on $166 \mathrm{kPa}$ NFS (Fig. 3e and Figure S2). Both MGAT5 and Galectin-3 are upregulated in transformed cells, and causal associated with invasion and metastasis [21]. Our results suggest that their interaction may be required for mechanosensing of ECM stiffness and cell migration. To explore this hypothesis, MGAT5 was deleted in GSC clones using CRISPR-Cas9 [31] and the absence of the enzyme checked by western blotting (Fig. 4a).

\section{MGAT5 knock out decreases migration on the $166 \mathrm{kPa}$ NFS, EMT and focal adhesions maturation}

Glycome analysis showed that $\beta 1,6 \mathrm{GlcNAc}$ branched tetra-antennary $\mathrm{N}$-glycans were absent in the $\mathrm{KO}$ cells with respect to WT, while the relative expression of triantennary $\mathrm{N}$ - glycans was increased (Fig. 4b). The major fucosylated N2M3 + N4H4F isoform group 2 is much less abundant in MGAT5 KO compared to WT (Figure S3). The remaining N2M3 + N4H4F structures observed in the MGAT5 KO GSCs (Fig. 4b) were most likely isomers equivalent in mass, notably bi- and tri- antennary with polylactosamine (Figure S3).

The MGAT5 KO GSCs grow at the same rate as wild type GSCs (Fig. 4c). However, in proliferation medium they formed multiple small and weakly adhering spheres rather than a single NS as seen for WT, suggesting that cell-to-cell adhesion is compromised (Fig. 4d). We previously reported a similar effect on NS formation with the MGAT5 inhibitor, phostine PST 3.1a on GSCs [32]. In agreement with this, we also observed a disaggregation of the MGAT5 KO GSCs NS and dispersion of the cells on NFSs, when grown in proliferation medium (Figure S5).

In differentiation medium, which promoted migration of WT GSC, migration of MGAT5 KO GSCs was significantly reduced on the $166 \mathrm{kPa}$ NFS only ( 2 times) (Fig. $4 \mathrm{e}$ and $\mathrm{f}$ ), highlighting the implication of MGAT5 activity in optimal rigidity sensing. Whereas cell dimensions of WT GSCs show a clear dependence on matrix stiffness, $\mathrm{KO}$ cells change shape much less as a function of stiffness (Fig. 5a-d).

The length and width of the MGAT5 KO GSCs did not vary according to the stiffness of the NFSs (Fig. 5b and c). Width/length ratios for MGAT5 KO GSCs compared to those of WT GSCs (Fig. 5d), revealing a reduction in morphological plasticity on $166 \mathrm{kPa}$ NFS.

The robust increases in ZEB1, N-CAD, SOX2, ZO1, Galectin 3, and Talin, Calpain2 and pFAK/FAK observed for WT GSCs on $166 \mathrm{kPa}$ NFS were not observed in MGAT5 KO GCS with the exception of SOX2 (Figs. 3e, 5 e, Figures $\mathrm{S} 2$ and $\mathrm{S} 4$ ). Thus FA maturation and signalling in MGAT5 KO cells was inhibited on $166 \mathrm{kPa}$ NFS and comparable to other NFSs stiffnesses. Thus MGAT5 $\mathrm{N}$-glycan branching is critically involved in glioblastoma mechanosensing and regulation of stiffness dependent cell morphology and motility (Fig. 6).

\section{Discussion}

Tumor cells undergo functionally important changes in protein glycosylation [33, 34], notably, increased Nglycan branching and extension with polylactosamine, the preferred ligands for galectins and regulation of cell surface receptors $[19,20]$. The galectin interaction with branched $\mathrm{N}$-glycans on integrins is associated with turnover and maturation of the FA, fibronectin fibrillogensis and actin microfilament remodelling [21, 30]. Knockdown of MGAT5 in cancer cells has been shown to reduce N-glycan branched on N-CAD and turnover of cell-cell adhesions, as well as cell migration [35]. Removal of three sites with branched N-glycans from NCAD did not alter surface expression but did reduced cancer cell migration and invasion. Here we examined the role of MGAT5 in the sensing of substratum stiffness by GSC, through FA formation and signalling. GSCs displayed an optimal migration on $166 \mathrm{kPa}$ NFS relative to higher or lower stiffness. Moreover, increases in galectin-3, talin, calpain2 and the pFAK/FAK ratio in WT GSC the 166 Pa NFS indicate optimal FA signalling 
A

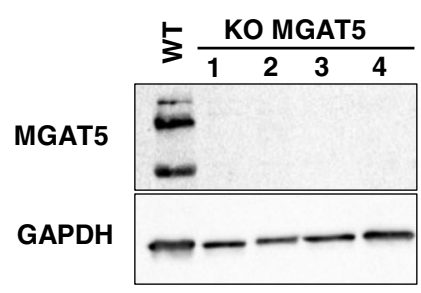

B

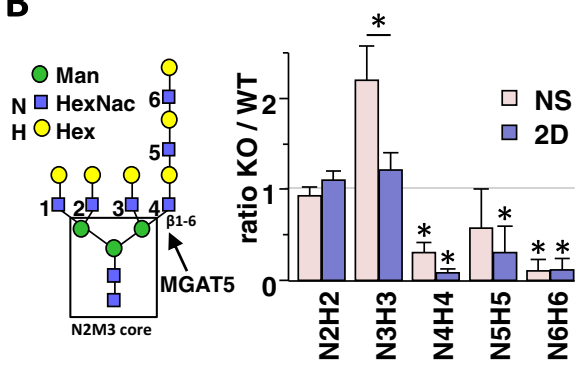

C

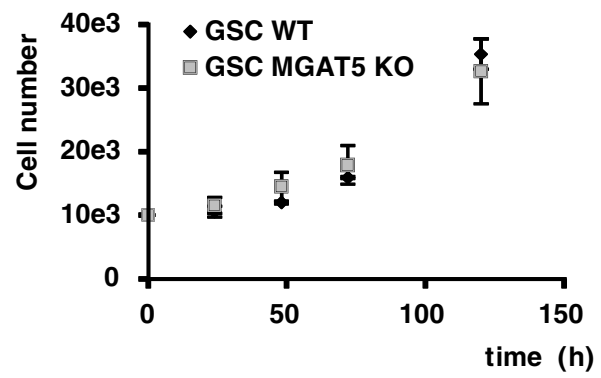

D WT

KO
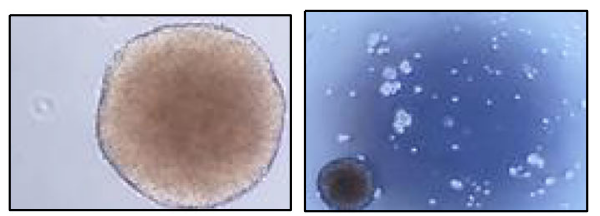

E

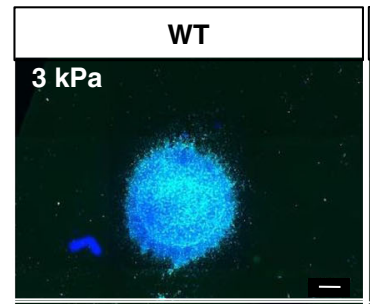

$166 \mathrm{kPa}$

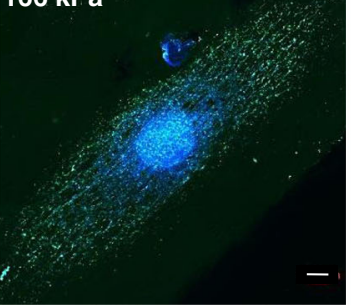

$166 \mathrm{kPa}$

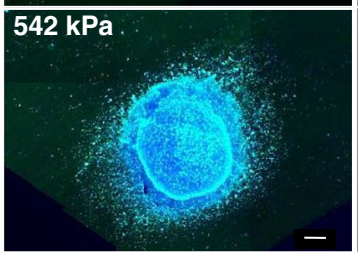

MGAT5 KO

$3 \mathrm{kPa}$

$1260 \mathrm{kPa}$

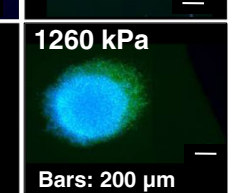

Hoechst Phalloidin
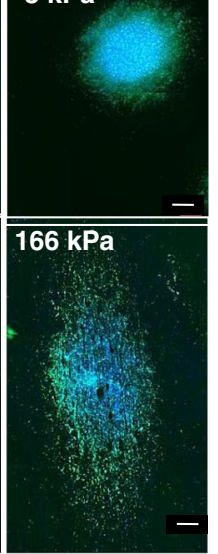

$542 \mathrm{kPa}$

$F$

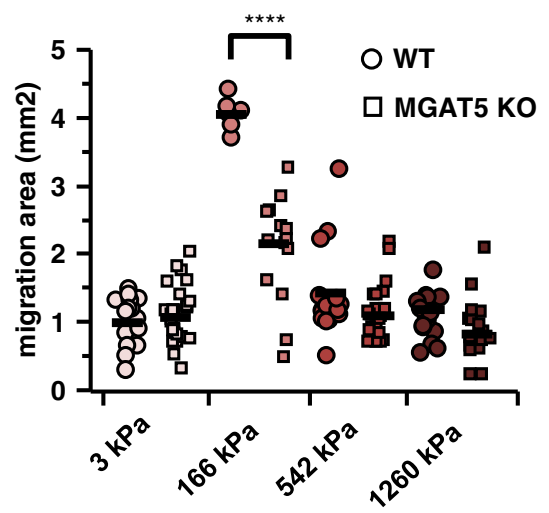

Fig. $4 \mathrm{KO}$ of MGAT5 decreases GSC migration at $166 \mathrm{kPa}$. a Western blot of MGAT5 expression in WT and 4 MGAT5 KO clones $(n=3)$. b LC-MS/ MS data for total bi- $(\mathrm{N} 2 \mathrm{H} 2)$, tri- $(\mathrm{N} 3 \mathrm{H} 3)$ and tetra- $(\mathrm{N} 4 \mathrm{H} 4)$ antennary $\mathrm{N}$-glycans expressed as a ratio of MGAT5 KO / WT reveals the loss of N4H4 and addition of polylactosamine $\left.>\mathrm{N} 4 \mathrm{H} 4 ;{ }^{*} p<0.05\right)$. Our analysis does not distinguish lactosamine isomer, which are therefore represented as minor structures in structures with $>\mathrm{N} 3 \mathrm{H} 3$ units. The N-glycans with masses $>\mathrm{N} 3 \mathrm{H} 3$ in $\mathrm{KO}$ cells, are most likely N2H2 and N3H3 with polylactosamine extensions with identical masses to N4H4 $(n=3)$. c Proliferation of WT and MGAT KO GSCs does not differ $(n=5)$. d Compared to WT GSC, NS formation is inhibited in MGAT5 KO GSCs. e Migration of WT and MGAT KO GSCs on fibres of various stiffnesses. F-Actin was stained with Phalloïdin (Green) and the nucleus stain with Hoechst 33342 (Blue). $\mathbf{f}$ Quantification of migration area in differentiation medium comparing WT and MGAT5 KO GSCS showing a significant reduction of migration of KOs at $166 \mathrm{kPa}(n=3$ with at least 6 GSCS NS per condition). Values of the figure correspond to the mean \pm SEM and statistical significance was determined using one-way ANOVA $\left({ }^{*} p<0,05\right.$; ** $p<0,01$; *** $\left.p<0,005 ;{ }^{* * *} p<0,001\right)$ 
A

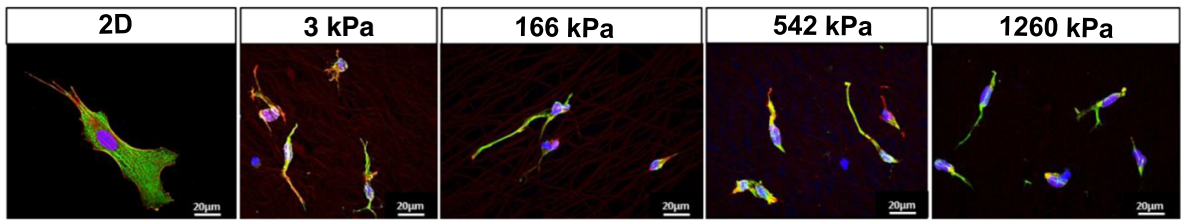

B

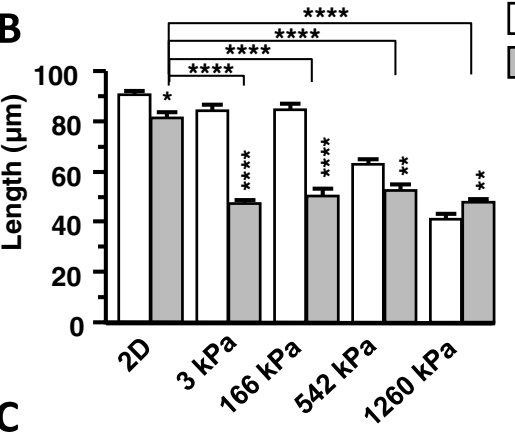

WT

MGAT5 KO

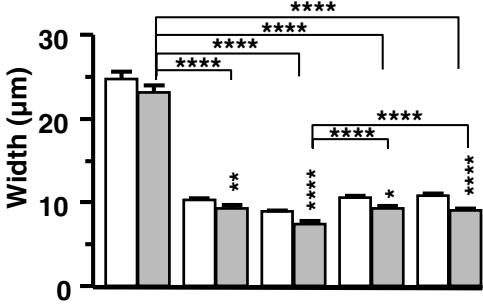

E

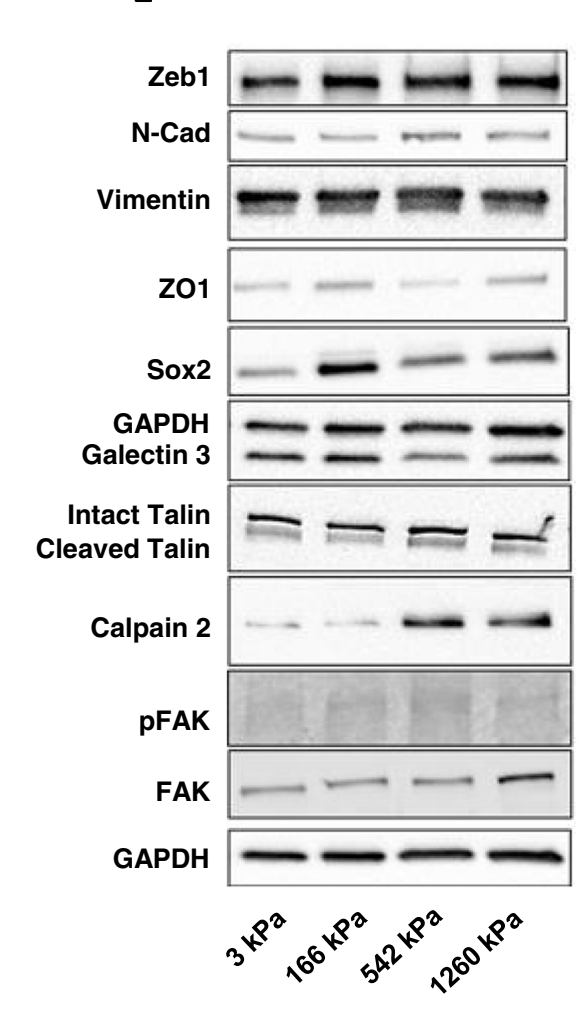

D
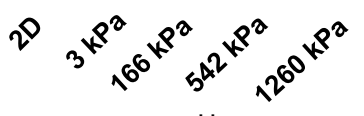

$\star \star$

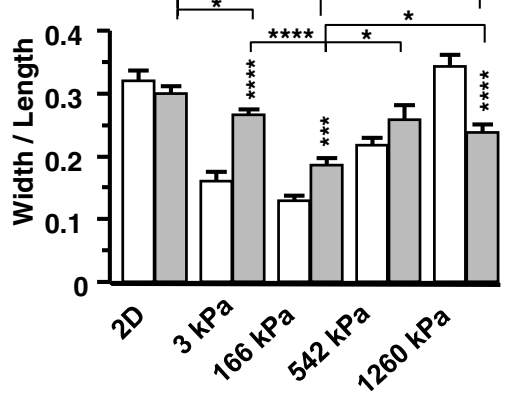

Fig. 5 MGAT5 KO modifies the expression of EMT and adhesome proteins. a MGAT5 KO GSCs were cultured on 2D and NFSs of different stiffnesses. Labelling: vinculin green, actin red (phalloidin) and DNA blue (Hoechst 33342). b Length, $\mathbf{c}$ Width and $\mathbf{d}$ aspect ratio of MGAT5 KO GSCs grown fibres of different stiffnesses were determined and compared to WT. Asterisks indicate significant differences between KO and WT ( $n=3$ with at least 86 cells by condition). e Western Blot of EMT and adhesome protein expression by MGAT5 KO GSCs ( $n=3$ to $n=4$ for each protein tested). Associated quantifications in Supp. Figure 4. Values of the figure correspond to the mean \pm SEM and statistical significance was determined using one-way ANOVA $\left({ }^{*} p<0,05 ;{ }^{* *} p<0,01 ;{ }^{* *} p<0,005 ;{ }^{* * *} p<0,001\right.$ )

and turnover consistent with the dynamics of galectinlattice model in cell migration $[18,21]$. We observed that a stiffness of $166 \mathrm{kPa}$ is sensed as optimal for migration even when the chemical signals given by the proliferation culture medium constrain them to NS phenotype. This critical value of $166 \mathrm{kPa}$ illustrates the physical crosstalk existing between cell applied forces and stiffnesses of the ECM to reach a maximum migration speed. Less or more stiffness do not appear to allow FA maturation and maximal cell migration. The increased amount of talin and cleaved talin observed using $166 \mathrm{kPa}$ NFS reflects the strengthening of the link 


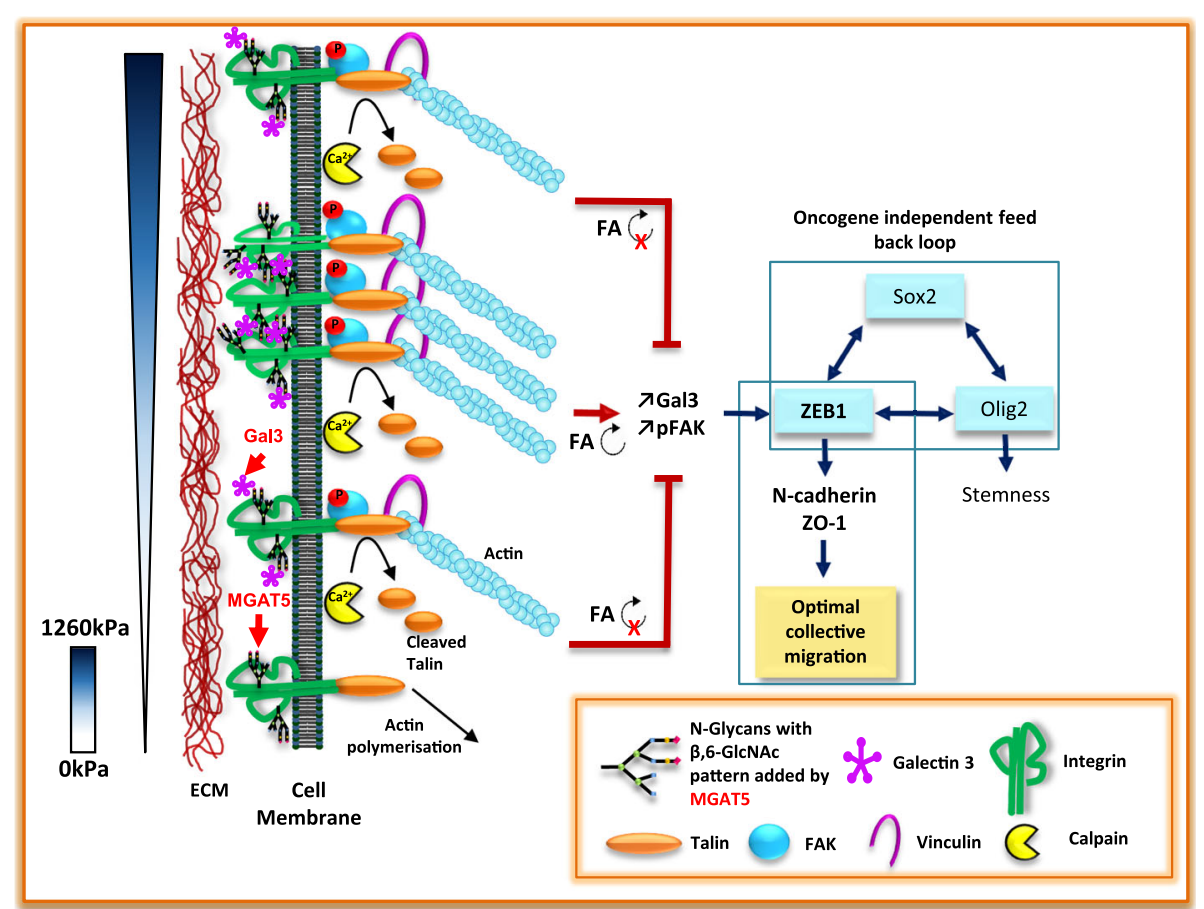

Fig. 6 MGAT5 involvement in mechanotransduction and cell migration rate control. One hundred sixty-six kilopascal is the optimal stiffness for integrin clustering controlled by MGAT5 glycosylation activity, focal adhesions (FA) turn-over and maturation (U) and galectin 3 (Gal3) upregulation. The resulting augmentation of FAK signalling increases expression of the mesenchymal marker ZEB-1 with subsequent increases of NCAD and ZO-1 expressions leading to increased cell collective migration rate. ZEB-1 appears as a hub integrating signalling information from the SOX2 transcription circuit, independent of the RTKs [8] and the MGAT5 restricted mechanotransduction depending on ECM stiffness (S)

between the integrin and the actin cytoskeleton in FAs $[36,37]$ and illustrates a role for talin as a tension sensor [38]. In addition, Calpain which expression increases in $166 \mathrm{kPa}$ NFS is known to cleave talin and FAK, thereby regulating both focal adhesions dynamics [17] and rigidity sensing [36]. In conclusion, measurement of the ECM stiffness and MGAT5-dependent N-glycan branching may be a better indicator of cancer cell invasiveness than either alone.

$\beta 1,6$ GlcNAc branched $\mathrm{N}$-glycans with polylactosamine extensions have higher affinities for galectin-3 than less branched structures [20]. We also noted that unlike NS, the relative expression of N3 branched glycans does not increase for 2D MGAT5 KO GSCs. Because formation and disassembly of integrin-mediated adhesions are regulated temporally and spatially during migration [39] we hypothesize the relative amounts of tri- and tetra- antennary $\mathrm{N}$-glycans control migration.

Interestingly, loss of MGAT5 expression severely reduced GSC migration speed on $166 \mathrm{kPa}$ NFS only and enhanced cell detachment from the NS generating cell dissemination. Cell detachment and dissemination of MGAT5 KO GSCs is also observed and increased when cells seeded on NFS of different stiffnesses grow in proliferation medium. In contrast to what was observed in WT GSCs, Galectin3 expression profile and pFAK/ FAK ratio in MGAT5 KO GSCs, didn't vary according to NFS rigidity. These results are in agreement with our previous data showing that inhibition of MGAT5 enzymatic activity by the phostine compound PST3.1a causes cell detachment and dysregulation of actin assembly subsequent to a reduction of FAK phosphorylation thereby causing reduced migration of Gli4 GSCs [32]. These data highlight the key role played by MGAT5 in regulation GSCs migration speed via FAK signalling. Cell migration is also a remarkable example of the close link existing between integrin signalling, assembly of the cytoskeleton and cell morphology [40]. In MGAT5 KO GSCs compared to WT GSCs, we observed a decrease in GSCs length. This morphological difference is associated with a decrease of calpain 2 and talin expression on 166 kPa NFS. Those results suggest a loss of FA maturation mediated by stiffness on MGAT5 KO GSCs. They also underline the impact of the NFS stiffness on galectin 3 expression modulation mediated by FA maturation and turn-over associated with MGAT5 expression. In conclusion these data are consistent with the reported observations that cell migration is the result of cell 
attachment and detachment regulated by the FA turnover in which FAK also plays a central role [41].

ZEB1 expression has been reported to play a central role in regulating GSCs migration [42]. The expression of ZEB1 did not vary with rigidity in MGAT5 KO GSCs compared to WT GSCs). In addition, the absence of ZEB1 expression modulation according to the different NFS rigidities highlights that MGAT5-mediated glycosylation is essential for mechanical environment sensing supported by a differentially regulated expression of ZEB1. ZEB1 was reported to enhance the expression of the mesenchymal marker N-CAD [43]. We observed that enhanced expression of ZEB1 on $166 \mathrm{kPa}$ NFS in WT is associated with an increase of N-CAD expression. In MGAT5 KO GSCs the loss of the ZEB1 expression modulation according to the NFS stiffness is accompanied by a loss in the differential expression of N-CAD. These results confirm that MGAT5-mediated glycosylation promotes the sensing of the mechanical properties of the microenvironment through FA maturation and promotes EMT at $166 \mathrm{kPa}$. Nevertheless, in MGAT5 KO GSC grown on $1260 \mathrm{kPa}$ NFS, we observed both an increase in Calpain2 and N-CAD expressions. The latter data indicates that in absence of MGAT5 expression, higher stiffness is required for membrane deformation in order to induce FA turn-over and EMT-like phenotype.

In addition to the cell-ECM interactions and signaling, cell-cell interactions, play a key role in collective cell migration [44] and N-CAD is reported to promote cancer cell migration [45]. In contrast to WT GSCs, ZO1 expression was down regulated in MGAT5 KO GSCs in NFS of the optimal stiffness of $166 \mathrm{kPa}$. Therefore we suggest that a deficient galectin lattice, lead to uneffective transmission of mechanical information orchestrated by FAs and cell-cell junctions unabling optimal migration and stiffness dependant EMT.

Beside the effects on cell migration and mesenchymal in MGAT5 KO GSCS the expression of SOX2 remains inducible according to the rigidity of the support as in WT GSCs. This result suggests that part of the stemness character is conserved independently of MGAT5 expression. In addition, we show that the action of SOX2 to reach a maximal velocity on NFS of stiffness of $166 \mathrm{kPa}$ is restricted to MGAT5 glycosylation activity and to ZEB1 expression modulation according to stiffnesses.

In conclusion, the absence of MGAT5 leads to a decrease in migration speed, EMT-like processes and FA turn-over and maturation through the inhibition of mechanotransduction. We propose that the mechanisms involving MGAT5 in EMT processes is mediated by fine sensing of the stiffness leading to ZEB1 expression modulation, and regulate key oncogenic functions [46], making MGAT5 as a serious target to treat cancer.

\section{Materials and methods 3D nanofibre matrix}

Polyacrylonitrile nanofibers were produced by electrospinning using a solution of $10 \% \mathrm{~W} / \mathrm{W}$ Polyacrylonitrile (Sigma Aldrich) dissolved in dimethylformamide (DMF, Sigma Aldrich). The electrospinning set-up (IME Medical Electrospinning, NL) was equipped with a rotating drum module located at a distance of $15 \mathrm{~cm}$ from the needle. In a classical experiment, a voltage of $20 \mathrm{kV}$ was applied and the rotating speed of the drum was set at $2000 \mathrm{rpm}$. To tune NFS mechanical properties, multiwalled carbon nanotubes (MWCNTs, Nanocyl, 95\% purity) were added in the Polyacrylonitrile solution and stabilized by adding Triton $\times 100$ (Sigma Aldrich) at a weight ratio of 1:50 of MWCNT/Triton. After electrospinning, the NFSs were cross-linked by heat treatment at $250{ }^{\circ} \mathrm{C}\left(4{ }^{\circ} \mathrm{C} / \mathrm{min}\right)$ during $2 \mathrm{~h}$ under air. Pieces of the NFSs were cut and sterilized using classical autoclave treatment before further biological use [7].

\section{Atomic force microscopy (AFM)}

Atomic force microscopy measurements were done using an Asylum MFP-3D head coupled to a Molecular Force Probe 3D controller (Asylum Research, Santa Barbara, CA, USA). Triangular silicon nitride cantilevers (MLCT, Veeco) with a nominal spring constant of 10 $\mathrm{pN} / \mathrm{nm}$ and half-opening angle of $35^{\circ}$ were used. The probe has a nominal length of $310 \mu \mathrm{m}$, width of $20 \mathrm{~nm}$, and resonance frequency of $7 \mathrm{kHz}$. Prior to each experiment, the cantilever spring constant was determined in liquid using the thermal noise method available within the MFP-3D software. Samples were glued to a Petri dish by means of carbon conductive double-faced adhesive tape, in order to minimize electrostatic interactions between the atomic force microscope tip and the sample, and were covered with $2 \mathrm{ml}$ of deionized water. After testing a range of loading forces on the sample surface, the measurements were performed in liquid and at room temperature with a maximum loading force of $\sim 300 \mathrm{pN}$ corresponding to a maximal indentation depth of $120 \mathrm{~nm}$. Higher loading force values (up to $1 \mathrm{nN}$ ) led to a stiffness overestimation due to a possible influence of the substrate.

The elastic deformation was obtained from the force curves as a function of the loading force applied by the tip. Young's modulus (E) was calculated for each force from the approaching part of the force curves as the recorded force curves exhibited hysteresis. It shows the viscoelastic behaviour of the sample [47], following a modified Hertz model [48], based on the work of Sneddon and further developed for different atomic force microscope tip shapes as described elsewhere [49]. A constant approach velocity of $6 \mu \mathrm{m} / \mathrm{s}$ was chosen, meaning a piezo-extension rate of $3 \mathrm{~Hz}$ to minimize 
hydrodynamic and viscoelastic artefacts [50]. The Poisson's ratio of the cells was assumed to be 0.5 , as suggested for incompressible materials [51]. The analysis of one image for each type of NFS is presented in supplementary figure 1 .

\section{Cell culture}

GBM cells isolation and primary cell culture were realized using the classical non-adherent neurospheres (NS) protocol adapted by Guichet et al [52]. GBM cells were cultured in two different conditions in DMEM/F12 medium supplemented with glucose, glutamine, insulin, $\mathrm{N} 2$ and ciprofloxacin. In the "proliferation" nonadherent condition, the culture flasks were pre-coated with poly-2-hydroxyethyl methacrylate (poly-HEME, Sigma) and the medium was also supplemented with Epidermal Growth Factor (EGF), Fibroblast Growth Factor (FGF), gentamycin, heparin, fungizone, fungin and B27. In this condition, GBM cells growing as NS is reminiscent of neural stem cells in vitro, express neural progenitors and stem cells markers (nestin, OLIG2, SOX2 etc.), self-renew and propagate tumours in immunocompromised animals. NS could be dissociated and reseeded. In the "differentiation" condition, also called "migration medium", the DMEM/F12 medium was supplemented with foetal bovine serum (0.5\%), fungizone and B27. For this latter condition, GBM cells dissociated or as NS were cultured in adherence on 2D (planar surfaces). These cells are called adherent cells. Also GBM cells dissociated or as NS are cultivated on NFs of various stiffnesses. The GSCs remained in culture during 5 days at $37^{\circ} \mathrm{C} / 5 \% \mathrm{CO} 2$.

To obtain NS with the same size, we used Corning 96 well round bottom ultra-low attachment microplates coated with a covalently bond hydrogel (Corning 7007). Dissociated GBM NS cultured in proliferation condition, were seeded at 7500 cells per well and remained in culture during 6 days until formation of single NS after sedimentation.

\section{MGAT5 knock-out}

MGAT5 KO GSCs were made using the CRISPR Cas 9 technique [31]. GSC transfection was carried out by electroporation with $1 \mu \mathrm{g}$ of CRISPR Cas 9 plasmid (Santa Cruz) per 1 million cells in Amaxa mouse neural stem cell Nucleofector. Transfected plasmid contained GFP for Fluorescence-activated cell sorting and to deposit one cell per well in Corning $^{\bullet} 96$ wells round bottom ultra-low attachment microplates. After proliferation and the formation of a single neurosphere, KO efficiency was checked by western blot.

\section{Quantification of migration}

Seven thousand five hundred cells same size NSs were deposited on NFSs of different stiffnesses in differentiation/migration medium and left to migrate for 5 days [7]. Migration imaging could be done from the top of the nanofibers matrix thanks to topoinduction process due to aligned nanofibers making whole migration area visible $\left(\mu \mathrm{m}_{2}\right)$. Imaging and quantifications were performed thanks to epifluorescence microscopy and ZEN 2012 software in counting number of cells, using DAPI staining. Migration capacity was quantified by measuring an area of migration. To measure migration areas, we subtracted the area of the NS containing non-migrating cells from the total area where cells were detected. Regarding collective migration, Gli4 cells were considerate as migrate collectively by forming aggregates composed at least of tens of tightly associated cells [7].

\section{Total cellular $\mathrm{N}$-glycan profiling}

Extracted membrane protein $(30 \mu \mathrm{g})$ was suspended in $30 \mu \mathrm{L}$ of $0.25 \%$ RapiGest SF, $50 \mathrm{mM}$ ammonium bicarbonate, $5 \mathrm{mM}$ DTT, heated at $85 \mathrm{oC}$ for $3 \mathrm{~min}$, then mixed with $1 \mu \mathrm{L}$ of PNGase F, $0.7 \mu \mathrm{L}$ of sialidase, and $20 \mu \mathrm{L}$ of $50 \mathrm{mM}$ ammonium bicarbonate, and incubated at $42 \mathrm{oC}$ for $2 \mathrm{~h}$ followed by $37 \mathrm{oC}$ overnight. Released $\mathrm{N}$-glycans were extracted with 4-5 volumes of $100 \%$ ethanol at $-80^{\circ} \mathrm{C}$ for $2 \mathrm{~h}$. The supernatant containing released $\mathrm{N}$-glycans was speed vacuumed to dry.

Pipet tips packed with $10 \mathrm{mg}$ porous graphitized carbon (PGC) for a bed volume of $50 \mu \mathrm{L}$ were washed with $500 \mu \mathrm{L}$ of $\mathrm{ddH}_{2} \mathrm{O}, 500 \mu \mathrm{L}$ of $80 \%$ acetonitrile $(\mathrm{ACN})$, and equilibrated with $500 \mu \mathrm{L} 0.1 \%$ trifluoroacetic acid (TFA). N-glycan pellets were dissolved in $50 \mu \mathrm{L}$ of $0.1 \%$ TFA and loaded into the microtips at a flow rate of $\sim 100 \mu \mathrm{L} / \mathrm{min}$, washed with $500 \mu \mathrm{L} 0.1 \%$ TFA, and $\mathrm{N}$-glycans eluted with $500 \mu \mathrm{L}$ of elution buffer $(0.05 \%$ TFA, $40 \%$ ACN). The eluted N-glycans were analysed by LC-MS/MS. Total glycan samples were applied to a nano-HPLC Chip using a Agilent 1260 series microwell-plate autosampler, and interfaced with a Agilent 6550 iFunnel Q-TOF MS (Agilent Technologies, Inc., Santa Clara, CA). The HPLC Chip (glycan Chip) had a $40 \mathrm{~nL}$ enrichment column and a $75 \mu \mathrm{m} \times 43 \mathrm{~mm}$ separation column packed with $5 \mu \mathrm{m}$ graphitized carbon as stationary phase. The mobile phase was $0.1 \%$ formic acid in water $(\mathrm{v} / \mathrm{v})$ as solvent $\mathrm{A}$, and $0.1 \%$ formic acid in $\mathrm{ACN}(\mathrm{v} / \mathrm{v})$ as solvent $B$. The flow rate at $0.3 \mu \mathrm{L} / \mathrm{min}$ with gradient schedule; $5 \%$ B (0-1 min); 5-20\% B (1-15 min); 20$70 \%$ B (15-16 min); 70\% B (16-19 min) and 70-5\% B (19-20 min). MS System was operated in positive ion mode at $2 \mathrm{GHz}$ Extended Dynamic Range, MS mode 
in low mass range $(1700 \mathrm{~m} / \mathrm{z})$ with $\mathrm{MS}$ setting at 8 MS (range $450-1700 \mathrm{~m} / \mathrm{z}$ ).

\section{MTT test}

Thirty thousand cells dissociated were seeded on NFSs of various stiffnesses or in 2D during 5 days. At day 1,3 , and 5 days of migration, $0.5 \mu \mathrm{g} / \mu \mathrm{l}$ of MTT (Sigma) was added in the medium during $3 \mathrm{~h}$ at $37^{\circ} \mathrm{C} / 5 \% \mathrm{CO} 2$. DMSO (sigma) was then added and the medium was transferred in 96 wells plates to be analysed by a Clariostar microplate reader.

\section{Cellular growth analysis}

Ten thousand cells were seeded in 96 wells plates precoated with poly-2-hydroxyethyl methacrylate (polyHEME, Sigma), and counted daily with Z2 counter (Beckman Coulter) every $24 \mathrm{~h}$ during 5 days. Before counting, GSC were dissociated with Trypsin 2.5\%/ EDTA $(10 \mathrm{mM})$ and incubated $10 \mathrm{~min}$ at $37^{\circ} \mathrm{C} / 5 \% \mathrm{CO} 2$ before particle counting.

\section{Immunostaining}

After 5 days of culture, Gli4 on NFS or 2D were fixed by a solution of $4 \%$ of PFA. Cells were blocked and permeabilized using a solution of PBS - triton 0.5\% - horse serum 5\%. Primary antibodies were incubated overnight at $4{ }^{\circ} \mathrm{C}$. The antibody used in immunofluorescence was Vinculin (Sigma Aldrich V9264) Fluorochrome-coupled secondary antibodies $(1 / 500)$ were incubated $2 \mathrm{~h}$ at room temperature. The actin cytoskeleton was stained with phalloidin and cell nuclei with Hoechst 33342. NFS and coverslips with GSCs were mounted in fluoromount medium.

\section{Microscopy}

Image capturing and Z-stack acquisition were performed using Confocal 2 Zeiss LSM 5 Live DUO for the single cells (Figs. 3a and 5a) and Widefield 1 - Zeiss Axioimager Z1/ Zen (with an apotome) microscopes for GSCs NS left to migrate for 5 days (Figs. 2a,b and 4e). Imaris $\times$ 64 8.1.2 software has been used for 3D image reconstitution. Quantifications were done using ZEN software. SEM images were performed using Hitachi S4800, Zeiss EVO HD15 (Fig. 1c).

\section{Western blot}

Proteins were extracted by submerging the NFS in RIPA buffer (+ phosphatase/protease inhibitors). Protein lysate were separated by SDS-PAGE. PVDF membranes were blocked by TBS-Tween $0.1 \%$ - milk $5 \%$. Primary antibodies were incubated overnight at $4{ }^{\circ} \mathrm{C}$. The antibodies used in western blot are: N-cadherin (N-CAD) (D4R1H) (Cell Signalling 13116S), Vimentin (D21H3) (Cell Signalling 5741S), ZO-1 (D7D12) (Cell Signalling 8193S),
TCF8/ZEB1 (D80D3) (Cell Signalling 3396S), Calpain-2 (Abcam ab155666) Galectin-3 (Abcam ab2785), Talin1/2 (Abcam ab11188), FAK (Abcam ab40794), phospho-FAK Y397 (Abcam ab81298), SOX2 (Abcam ab97959), and GAPDH as a loading control (Millipore MAB374). Horseradish peroxidase-coupled secondary antibodies were incubated $2 \mathrm{~h}$ at room temperature. The Chemidoc XRS + imager was used for chemiluminescence detection. The pixel quantifications were done using Image Lab software.

\section{Statistical analysis}

Forces were analysed using the Asylum Research software. All data are reported as mean \pm standard error of the mean and are at least an $n=3$. ANOVA test was used for comparison between samples. Statistical analysis of the data was performed with Prism GraphPad.

\section{Supplementary Information}

The online version contains supplementary material available at https://doi. org/10.1186/s13046-021-01925-7.

Additional file 1: Figure S1. Atomic Force Microscopy force-volume maps. (A, B, C, D) 3D reconstructions of height of the contact point of control, $0.0015 \% \mathrm{~W} / \mathrm{W}$ of MWCNT, $0.00625 \% \mathrm{w} / \mathrm{w}$ and $0.05 \% \mathrm{w} / \mathrm{w}$ samples, respectively. Histograms of the associated Young's modulus $E$ fitted with a Gaussian distribution. Stiffness values given in the text correspond to the mean \pm SD of 5 independent elasticity maps. Statistical significance was determined using one-way ANOVA with post hoc Tukey's Honest Significant Difference test for multiple comparisons. $P$ values of less than 0.05 were considered significant. (D) 3D-reconstruction of the contact point's height. Figure S2. Western Blot quantification of WT GSC proteins expression. Each western blot quantification was performed three to seven times and normalized with respect to GAPDH expressions and sum. Bands were quantified using the Bio-Rad Chemidoc and the image lab software. Data are presented as mean +/- SEM and statistical significance was determined using one-way ANOVA (* $p<0,05$; ** $p<0,01$; *** $\left.p<0,005 ;^{* * * *} p<0,001\right)$. Figure S3. Examples of MS analysis and quantification of fucosylated glycans. Glycans were isolated from wild type (WT) or MGAT5 KO (1.2) GSCs cultivated either as neurospheres (NS) in proliferation medium or as adherent cells (ADH) in 2D in differentiation medium The minor structures with identical masses, group 2 and 1 are likely to be isomers, for example two linear $\mathrm{N}$-acetyllactosamine units on a bi- rather than tri - antennary N-glycan. (A, B) MS analysis and quantification triantenate glycancs with a fucosylated core of. (B, C, D) MS analysis and quantification of tri-antenate glycans di-fucosylated on the branches. ( $E_{\text {, }}$ F) MS analysis and quantification tetra-antenate glycans mono fucosylated on the branches. Data are presented as mean +/- SEM. Figure S4. Western Blot quantification of MGAT5 KO GSC proteins expression. Each western blot quantification was performed three to four times and normalized with respect to GAPDH expressions and sum. Bands were quantified using the Bio-Rad Chemidoc and the image lab software. Data are presented as mean $+/-$ SEM and statistical significance was determined using one-way ANOVA (* $p<0,05 ;{ }^{* *} p<0,01$; ${ }^{* * *} p<0,005 ;{ }^{* * * *} p<$

$0,001)$. Figure S5. MGAT5 KO GSC migration in proliferation medium compared to WT GSCs. (A) Pictures of WT and MGAT5 KO WT GSCs migration behaviour in proliferation medium of WT GSCs at every stiffnesses. Nucleus stain with Hoechst 33342. (B) Quantification 5 days after NS plating of migration area $\left(\mu \mathrm{m}^{2}\right)$ in the proliferation condition of WT GSCs and MGAT5 KO GSCs. Data are presented as mean +/- SEM and statistical significance was determined using one-way ANOVA $(* p<0,05$; ${ }^{* *} p<0,01$; $\left.{ }^{* *} p<0,005 ;{ }^{* * *} p<0,001\right)$. 


\section{Acknowledgements}

DC and NB thank INSERM for the financial support (INSERM/INCA project PC201216 Gliomatrack) and Jacques Vignon and Jan de Weille for the critical reading of the manuscript, Alexandra Ott and Herve de Laborde de Monpezat, and the MENRT fellowship (CBS2 Doctoral School).

\section{Authors' contributions}

Conception and design of study: E.M., N.B., D.C. Project Supervision: N.B., D.C. Carried out the experiments/Acquisition of data: E.M., C.F., C.Z., M.M.-F. Analysis and/or interpretation of data: E.M., C.Z., J. W. D., M.M.-F. Drafting the manuscript: E.M., N.B., D.C. Revising the manuscript critically for important intellectual content: C.F., D.C., J.C., T.I., J. W. D., E.M., N.B. Providing Glioblastoma Stem Cells: L.B., J.P.H, H.D. Initial Work on nanofiber: E.M., A. S, DOl: https://doi.org/10.1038/s41598-019-51108-w. The authors read and approved the final manuscript.

\section{Funding}

SATT AXLR

MENRT fellowship (CBS2 Doctoral School)

INSERM/INCA project PC201216 (Gliomatrack)

\section{Availability of data and materials}

The datasets during and/or analysed during the current study available from the corresponding author on reasonable request.

\section{Declarations}

\section{Ethics approval and consent to participate}

Work based on primary cell culture established by P-O Guichet et al. DOI: https://doi.org/10.1002/glia.22429

\section{Consent for publication}

E.M., C.F., C.Z., M.M.-F, T.I., A.S., L.B., J.C., J.P.H, H.D., J. W. D., D.C. and N.B.

\section{Competing interests}

University of Montpellier deposited a patent related to the 3D nanofiber network (Feb. 16, 2018, priority number WO2019158724). Dr. E.M., A.S., D.C. and N.B. are designed as co-inventors. Dr. C.F., C.Z., M.M.-F, J. W. D., J.C., T.I., L.B., J.P.H, and H. D declare no potential conflict of interest.

\section{Author details}

'Institut des Neurosciences de Montpellier (INM) U-1051, University of Montpellier, 80 rue Augustin Fliche, Hôpital Saint-Eloi, 34091 Montpellier, Cedex 5, France. ${ }^{2}$ School of Engineering and Materials Science, Queen Mary University of London, London E1 4NS, UK. ${ }^{3}$ Institut Européen des Membranes, IEM, UMR 5635, University of Montpellier, ENSCM, CNRS, Montpellier, France. ${ }^{4}$ École nationale supérieure de chimie de Montpellier, ENSCM, 240 Avenue du Professeur Emile Jeanbrau, 34090 Montpellier, France. ${ }^{5}$ Lunenfeld-Tanenbaum Research Institute, Mount Sinai Hospital, 600 University Ave., Toronto, ON M5G 1X5, Canada. 'Department of Molecular Genetics, and Department of Laboratory Medicine and Pathobiology, University of Toronto, Toronto, ON M5S 1A8, Canada. Institut Charles Coulomb, UMR 5221, University of Montpellier, CNRS, Montpellier, France.

Received: 14 December 2020 Accepted: 23 March 2021

\section{Published online: 24 April 2021}

\section{References}

1. Scherer HJ. Structural development in gliomas. Am J Cancer. 1938;34:333-51 https://doi.org/10.1158/ajc.1938.333.

2. Cuddapah VA, Robel S, Watkins S, Sontheimer H. A neurocentric perspective on glioma invasion. Nat Rev Neurosci. 2014). https://doi.org/10.1038/nrn3 765;15(7):455-65.

3. Barnes JM, Przybyla L, Weaver VM. Tissue mechanics regulate brain development, homeostasis and disease. J Cell Sci. 2017;130(1):71-82. https:// doi.org/10.1242/jcs.191742.

4. Watkins $\mathrm{S}$, Sontheimer $\mathrm{H}$. Hydrodynamic cellular volume changes enable glioma cell invasion. J Neurosci. 2012;31:17250-9. https://doi.org/10.1523/ JNEUROSCI.3938-11.2011.Hydrodynamic.
5. Xiwei Zheng DSH, Cong BI, Brooks M. Biomechanical and biochemical remodeling of stromal extracellular matrix in cancer. Anal Chem. 2015;25: 368-79 https://doi.org/10.1016/j.cogdev.2010.08.003.Personal.

6. Iser IC, Pereira MB, Lenz G, Wink MR. The epithelial-to-Mesenchymal transition-like process in Glioblastoma: an updated systematic review and in Silico investigation. Med Res Rev. 2017;37(2):271-313. https://doi.org/10.1 002/med.21408

7. Saleh A, Marhuenda E, Fabre C, Hassani Z, de Weille J, Boukhaddaoui H, et al. A novel 3D nanofibre scaffold conserves the plasticity of glioblastoma stem cell invasion by regulating galectin-3 and integrin- $\beta 1$ expression. Sci Rep. 2019;9(1):1-14. https://doi.org/10.1038/s41598-019-51108-w.

8. Singh DK, Kollipara RK, Vemireddy V, Yang XL, Sun Y, Regmi N, et al. Oncogenes activate an autonomous transcriptional regulatory circuit that drives Glioblastoma. Cell Rep. 2017;18(4):961-76. https://doi.org/10.1016/j. celrep.2016.12.064

9. Paszek MJ, Dufort CC, Rossier O, Bainer R, Mouw JK, Godula K, et al. The cancer glycocalyx mechanically primes integrin-mediated growth and survival. Nature. 2015;511:319-25. https://doi.org/10.1038/nature13535.The.

10. Hu YL, Lu S, Szeto KW, Sun J, Wang Y, Lasheras JC, et al. FAK and paxillin dynamics at focal adhesions in the protrusions of migrating cells. Sci Rep. 2014:4(1):1-7. https://doi.org/10.1038/srep06024.

11. Horton ER, Humphries JD, James J, Jones MC, Askari JA, Humphries MJ. The integrin adhesome network at a glance. J Cell Sci. 2016;129(22):4159-63. https://doi.org/10.1242/jcs.192054.

12. Mitchison T, Kirschner M. Cytoskeletal dynamics and nerve growth. Neuron. 1988;1(9):761-72. https://doi.org/10.1016/0896-6273(88)90124-9.

13. Elosegui-Artola A, Bazellières E, Allen MD, Andreu I, Oria R, Sunyer R, et al. Rigidity sensing and adaptation through regulation of integrin types. Nat Mater. 2014;13(6):631-7. https://doi.org/10.1038/nmat3960.

14. Goult BT, Yan J, Schwartz MA. Talin as a mechanosensitive signaling hub. J Cell Biol. 2018;217(11):3776-84. https://doi.org/10.1083/jcb.201 808061.

15. Carisey A, Tsang R, Greiner AM, Nijenhuis N, Heath N, Nazgiewicz A, et al. Vinculin regulates the recruitment and release of core focal adhesion proteins in a force-dependent manner. Curr Biol. 2013;23(4):271-81. https:// doi.org/10.1016/j.cub.2013.01.009.

16. Bauer MS, Baumann F, Daday C, Redondo P, Durner E, Jobst MA, et al. Structural and mechanistic insights into mechanoactivation of focal adhesion kinase. Proc Natl Acad Sci U S A. 2019;116(14):6766-74. https://doi. org/10.1073/pnas.1820567116.

17. Kerstein PC, Patel KM, Gomez XTM. Calpain-Mediated Proteolysis of Talin and FAK Regulates Adhesion Dynamics Necessary for Axon Guidance. J Neurosci. 2017;37(6):1568-80. https://doi.org/10.1523/JNEUROSCI.2769-16.2 016.

18. Goetz JG, Joshi B, Lajoie P, Strugnell SS, Scudamore T, Kojic LD, et al. Concerted regulation of focal adhesion dynamics by galectin-3 and tyrosine-phosphorylated caveolin-1. J Cell Biol. 2008;180(6):1261-75. https:// doi.org/10.1083/jcb.200709019.

19. Lau KS, Partridge EA, Grigorian A, Silvescu Cl, Reinhold VN, Demetriou M, et al. Complex N-glycan number and degree of branching cooperate to regulate cell proliferation and differentiation. Cell. 2007;129(1):123-34. https://doi.org/10.1016/j.cell.2007.01.049.

20. Partridge EA. Regulation of Cytokine Receptors by Golgi N-Glycan Processing and Endocytosis. Science (80-. ). 2004;306:120-4 http://www. sciencemag.org/cgi/doi/10.1126/science.1102109\%0Apapers3://publication/ doi/10.1126/science.1102109.

21. Lagana A, Goetz JG, Cheung P, Dennis JW, Nabi IR, Lagana A, et al. Galectin Binding to Mgat5-Modified N-Glycans Regulates Fibronectin Matrix Remodeling in Tumor Cells Galectin Binding to Mgat5-Modified N-Glycans Regulates Fibronectin Matrix Remodeling in Tumor Cells. Mol Cell Biol. 2006; 26:3181-93. https://doi.org/10.1128/MCB.26.8.3181.

22. Stewart DC, Rubiano A, Dyson K, Simmons CS. Mechanical characterization of human brain tumors from patients and comparison to potential surgical phantoms. PLoS One. 2017;12(6):e0177561. https://doi.org/10.1371/journal. pone. 0177561

23. Bangasser BL, Shamsan GA, Chan CE, Opoku KN, Tüzel E, Schlichtmann BW, et al. Shifting the optimal stiffness for cell migration. Nat Commun. 2017; 8(1):1-10. https://doi.org/10.1038/ncomms15313.

24. Weisenberger MC, Grulke EA, Jacques D, Rantell T, Andrews R. Enhanced mechanical properties of polyacrylonitrile/multiwall carbon nanotube 
composite fibers. J Nanosci Nanotechnol. 2003;3(6):535-9. https://doi.org/1 0.1166/jnn.2003.239

25. Siebzehnrubl FA, Reynolds BA, Vescovi A, Steindler DA, Deleyrolle LP. The origins of glioma: E pluribus Unum? Glia. 2011;59(8):1135-47. https://doi. org/10.1002/glia.21143

26. Beadle C, Assanah MC, Monzo P, Vallee R, Rosenfeld SS, Canoll P. The Role of Myosin II in Glioma Invasion of the Brain. Seikagaku. 2010;82:327-31 https://doi.org/10.1091/mbc.E08.

27. Petrie RJ, Doyle AD, Yamada KM. Random versus directionally persistent cell migration. Mol Cell. 2010;10:538-49 https://doi.org/10.1038/nrm2729.Ra ndom.

28. Xu W, Mezencev R, Kim B, Wang L, McDonald J, Sulchek T. Cell Stiffness Is a Biomarker of the Metastatic Potential of Ovarian Cancer Cells. PLoS One. 2012;7 https://doi.org/10.1371/journal.pone.0046609.

29. Swaminathan V, Fischer RS, Waterman CM. The FAK-Arp2/3 interaction promotes leading edge advance and haptosensing by coupling nascent adhesions to lamellipodia actin. Mol Biol Cell. 2016;27:1085-100 https://doi. org/10.1091/mbc.E15-08-0590.

30. Goetz JG. Bidirectional control of the inner dynamics of focal adhesions promotes cell migration. Cell Adhes Migr. 2009; https://doi.org/10.4161/ca m.3.2.7295.

31. Doetschman T, Georgieva T. Gene editing with CRISPR/Cas9 RNA-directed nuclease. Circ Res. 2017;120(5):876-94. https://doi.org/10.1161/CIRCRESA HA.116.309727.

32. Hassani Z, Saleh A, Turpault S, Khiati S, Morelle W, Vignon J, et al. Phostine PST3.1a Targets MGAT5 and Inhibits Glioblastoma-Initiating Cell Invasiveness and Proliferation. Mol Cancer Res. 2017;15:1376-88 https://doi.org/10.1158/1 541-7786.MCR-17-0120.

33. Pinho SS, Reis CA. Glycosylation in cancer: mechanisms and clinical implications. Nat Rev Cancer. 2015;15(9):540-55. https://doi.org/10.1038/nrc3 982.

34. Lau KS, Dennis JW. N-Glycans in cancer progression. Glycobiology. 2008; 18(10):750-60. https://doi.org/10.1093/glycob/cwn071.

35. Guo H, Nairn A, Dela Rosa M, Nagy T, Zhao S, Moremen K, et al. Transcriptional regulation of the protocadherin $\beta$ cluster during her-2 protein-induced mammary tumorigenesis results from altered $\mathrm{N}$-glycan branching. J Biol Chem. 2012;287(30):24941-54. https://doi.org/10.1074/jbc. M112.369355.

36. Saxena M, Changede R, Hone J, Wolfenson H, Sheetz MP. Force-induced Calpain cleavage of Talin is critical for growth, adhesion development, and rigidity sensing. Nano Lett. 2017;17(12):7242-51. https://doi.org/10.1021/acs. nanolett.7b02476.

37. Bosch-Fortea M, Martín-Belmonte F. Mechanosensitive adhesion complexes in epithelial architecture and cancer onset. Curr Opin Cell Biol. 2018;50:42-9 https://doi.org/10.1016/j.ceb.2018.01.013.

38. Klapholz B, Brown NH. Talin - the master of integrin adhesions. J Cell Sci. 2017:130(15):2435-46. https://doi.org/10.1242/jcs.190991.

39. Huttenlocher A, Horwitz AR. Integrins in cell migration. Cold Spring Harb Perspect Biol. 2011;3(9):1-16. https://doi.org/10.1101/cshperspect.a005074.

40. Bridgewater RE, Norman JC, Caswell PT. Integrin trafficking at a glance. J Cell Sci. 2012;125(16):3695-701. https://doi.org/10.1242/jcs.095810.

41. Ilić D, Furuta Y, Kanazawa S, Takeda N, Sobuet K, Nakatsuji N, et al. Reduced cell motility and enhanced focal adhesion contact formation in cells from FAK-deficient mice. Nature. 1995;377(6549):539-44. https://doi.org/10.1038/3 $77539 a 0$.

42. Euskirchen P, Radke J, Schmidt MS, Heuling ES, Kadikowski E, Maricos M, et al. Cellular heterogeneity contributes to subtype-specific expression of ZEB1 in human glioblastoma. PLoS One. 2017;12 https://doi.org/10.1371/ journal.pone.0185376.

43. Chen Y, Lu X, Montoya-Durango DE, Liu YH, Dean KC, Darling DS, et al. ZEB1 regulates multiple oncogenic components involved in uveal melanoma progression. Sci Rep. 2017;7(1):1-14. https://doi.org/10.1038/s41 598-017-00079-x.

44. Friedl P, Mayor R. Tuning collective cell migration by cell - cell junction. Regulation. Cold Spring Harb Perspect Biol. 2017;9(4):a029199. https://doi. org/10.1101/cshperspect.a029199.

45. Zhou W, Fong MY, Min Y, Somlo G, Liu L, Palomares MR, et al. Cancersecreted miR-105 destroys vascular endothelial barriers to promote metastasis. Cancer Cell. 2014;25(4):501-15. https://doi.org/10.1016/j.ccr.2014. 03.007.
46. Chen L, Gibbons DL, Goswami S, Cortez MA, Ahn YH, Byers LA, et al. Metastasis is regulated via microRNA-200/ZEB1 axis control of tumour cell PD-L1 expression and intratumoral immunosuppression. Nat Commun. 2014;5 https://doi.org/10.1038/ncomms6241.

47. Svaldo Lanero T, Cavalleri O, Krol S, Rolandi R, Gliozzi A. Mechanical properties of single living cells encapsulated in polyelectrolyte matrixes. J Biotechnol. 2006;124(4):723-31. https://doi.org/10.1016/j.jbiotec.2006.02.016.

48. Hertz H. Ueber die Berührung fester elastischer Körper. J Fur Die Reine Und Angew Math. 1882;1882(92):156-71. https://doi.org/10.1515/crll.1882.92.156.

49. Martin M, Benzina O, Szabo V, Végh A-G, Lucas O, Cloitre T, et al. Morphology and Nanomechanics of sensory neurons growth cones following peripheral nerve injury. PLoS One. 2013;8(2):e56286. https://doi. org/10.1371/journal.pone.0056286.

50. Radmacher M, Fritz M, Kacher CM, Cleveland JP, Hansma PK. Measuring the viscoelastic properties of human platelets with the atomic force microscope. Biophys J. 1996;70(1):556-67. https://doi.org/10.1016/50006-34 95(96)79602-9.

51. T. International Society of Biorheology, Ohayon J, Picart C, Tracqui P. An extended relationship for the characterization of Young's modulus and Poisson's ratio of tunable polyacrylamide gels: Pergamon Press; 2006. https://content-iospress-com.gate2.inist.fr/articles/biorheology/bir442. (Accessed 25 Sept 2018)

52. Guichet P-O, Bieche I, Teigell M, Serguera C, Rothhut B, Rigau V, et al. Cell death and neuronal differentiation of glioblastoma stem-like cells induced by neurogenic transcription factors. Glia. 2013;61(2):225-39. https://doi.org/1 $0.1002 /$ glia.22429.

\section{Publisher's Note}

Springer Nature remains neutral with regard to jurisdictional claims in published maps and institutional affiliations.

Ready to submit your research? Choose BMC and benefit from:

- fast, convenient online submission

- thorough peer review by experienced researchers in your field

- rapid publication on acceptance

- support for research data, including large and complex data types

- gold Open Access which fosters wider collaboration and increased citations

- maximum visibility for your research: over $100 \mathrm{M}$ website views per year

At BMC, research is always in progress.

Learn more biomedcentral.com/submissions 